\title{
Recovery of Heavy Metal Using Solvent Impregnated Resin (SIR) Coupled with Donnan Dialysis
}

\author{
Dalila Berdous ${ }^{1,2^{*}}$, Djamel Eddine Akretche ${ }^{1}$ \\ ${ }^{1}$ Laboratory of Hydrometallurgy and Inorganic Molecular Chemistry, Faculty of Chemistry, University of Sciences and Technology \\ Houari Boumediene, Algiers, Algeria; ${ }^{2}$ Center of Research in Physical and Chemical Analysis (CRAPC), Algiers, Algeria. \\ Email: *dalila2016@gmail.com
}

Received July $17^{\text {th }}, 2012$; revised August $18^{\text {th }}, 2012$; accepted September $21^{\text {st }}, 2012$

\begin{abstract}
A membrane process for metal recovery from aqueous solutions was studied. Metal ions diffused from the feed compartment to the stripping compartment through an hybrid Donnan dialysis which consists to combine two ion exchange membranes with solvent impregnated resin (SIR). The aim of this work is to study the recovery of $\mathrm{Pb}(\mathrm{II}), \operatorname{Ag}(\mathrm{I})$ and $\mathrm{Cu}$ (II) from nitrate solutions by using SIR combined with classical Donnan dialysis. The resin has been prepared by impregnating the Amberlite XAD-4 using three different extractants namely: di(2-ethylhexyl)phosphine acide $\left(\mathrm{D}_{2}\right.$ EHPA), tris-octyl phosphine oxide (TOPO) and Diphenylthiourea (DPT). Experiments were performed as a function of nature of the extractant impregnated on the XAD-4 resin as well as the concentration in the resin phase, the stripping $\mathrm{pH}$, the concentration ratio of metal ions in the feed compartment and the nature of the counter ions in strip compartment. The results show that the $\mathrm{D}_{2}$ EHPA is the better extractant for the metal ions used in this work, and it's shown a good selectivity for the separation between ions.
\end{abstract}

Keywords: Donnan Dialysis; Hybrid Process; Amberlite Xad-4; Solvent Impregnated Resin; D2EHPA; Topo; Dipehenylthiourea

\section{Introduction}

In recent years increasing interest in environment protection, economy of energy, as well as process optimization and the continuous progress in fundamental chemistry have produced an important development of new chemical separation techniques. The need of more specific systems for dilute metal recovery from both ecological and economic aspects has led to the development of the synthesis of new extractants, exchangers and adsorbents. These products have improved significantly the selectivity and efficiency of a large number of separation process techniques such as extraction with solvent supported liquid membranes, precipitation, etc. Among these new products, Solvent Impregnated Resins (SIR) has been postulated as a new technological alternative for problems associated with metal separation and recovery [1].

The solvent impregnated resins have been shown to be effective sorbent for the selective recovery of metal ions from aqueous solutions [2]. They combine not only the advantages of resin ion exchange for processing dilute liquors with specific properties of the extractants, but also a high distribution ratio and selectivity characteristic

*Corresponding author. of the extractants dissolved in a liquid organic phase with the simplicity of equipment and operation characteristic of solid ion-exchange technology [3]. It was well recognized that the impregnated extractants can exhibit strong affinity for the polymeric matrix but still behave as in the liquid state $[4,5]$. SIR was introduced in hydro- metallurgical applications by Warshawsky $[3,6]$.

Development of chelating materials for solid-phase extraction has gained special attention due to the advantages in the use of these substances in metal ion enrichment. These advantages include high degree of selectivity by controlling $\mathrm{pH}$, versatility, durability, good metal loading capacity and enhanced hydrophilicity. Chelating ligands have been functionalized in several support materials, including commercially available XAD resin series. Amberlite XAD is resin widely used to develop several chelating materials for pre-concentration procedures due to its good physical and chemical properties such as porosity, high surface area, durability, and purity [7-9]. Amberlite XAD-4 has been often used as a solid sorbent to prepare ligand-loated resin. Recently, the XAD-4 resin, impregnated with many compound as complexing agents has been used for pre-concentration of heavy metals [10-13]. 
Some authors have studied the recovery of different metals using Amberlite XAD-2 resins impregnated with different extractants [14-16].

Conventional separation techniques, such as fractional crystallization and fractional precipitation, are inefficient. In addition, solvent extraction techniques have been replaced by solid phase extraction procedures, such as chromatography by extraction resin. Solid phase extraction procedures combine the advantages of high selectivity of solvent extraction and high efficiencies of chromatographic separation [17,18], and they separates elements with high purity. Jia, Wang et al. [19] have used an extractant resin, with styrene-divinyl benzene copolymer as support and (HEH [EHP]) as the extractant, and its performance in separating rare earth, such as gadolinium and terbium.

Because of these advantages, extraction resin and their loaded chromatographic separation of metal ions have been under development since 1970. Many papers on the adsorption of metal ions have focused on the use of resins containing organo-phosphorus acids as extractants $[20,21]$.

Amberlite XAD-4 has been often used as a solid sorbent to prepare a ligand-loaded resin. Recently, the $\mathrm{XAD}-4$ resin impregnated with many compounds as complexing agents has been used for pre-concentration of heavy metals. The use of biological materials for effective removal and pre-concentration of heavy metals from contaminated waters has emerged as a potential alternative method to conventional treatment techniques of all the pre-concentration methods, bio-sorption by microorganisms immobilized on solid support seems to be the most effective pre-concentration methods, due to their higher recoveries, economical advantages, simplicity and environmental safety [22,23]. M. Dogru et al. [24] proposed the use of bacillussubtilis immobilized on Amberlite XAD-4 as new bio-sorbent in trace metal determination. This procedure was applied to the determination of $\mathrm{Cu}^{2+}$ and $\mathrm{Cd}^{2+}$ in aqueous solutions.

T. Saitoh et al. [25] have used the styrene-divinyl benzene XAD-4 for the collection of precious metals from water by impregnated them with trioctylamine (TOA), it was found that this resin was useful for concentrating precious metals such as: platinium, gold and palladium.

In this work, the combination of the SIR with ion exchange membranes is used to perform separationconcentration of lead, copper and silver by means of Donnan dialysis. Recovery of copper, silver and lead were investigated with new hybrid process which combined Donnan Dialysis to SIR. These three metals are chosen because they are often associated in ores and industrial solutions.

\section{Experimental Part}

\subsection{Membranes}

The cation exchange membrane used is the CMX membrane containing poly-sulfonated groups and furnished by Tokuyama Soda co ltd. Its exchange capacity is 1.62 meq $\cdot \mathrm{g}^{-1}$ and a thickness of $175 \mu \mathrm{m}$. The water used throughout the work was deionised water.

\subsection{Reagents and Solutions}

Copper(II) nitrate, lead(II) nitrate and silver(I) nitrate (analytical grade reagents) were purchased from Fluka. All reagents were used as received without further purification. The aqueous phases were prepared by dissolving the different reagents in deionised water.

Di(2-ethylhexyl)phosphoric acid (D2EHPA) was the product of Sigma. It had a purity of about $95 \%$ and was used without further purification. Trioctyl phosphin oxide (TOPO) was product of Fluka, it had a purity of about 95\%. Diphenyl-thiourea was the product of Aldrich and its purity is $98 \%$. Metal nitrates, n-hexane and chloroform as a solvent, and others inorganic chemicals were supplied by Fluka as analytical reagent grade and used as received.

The Amberlite XAD-4 macro-porous resin (styrenedivinyl-benzene copolymer) is a polymeric adsorbent, supplied as white insoluble beads. It's a non ionic crosslinked polymer which derives its adsorptive properties from its patented macro-reticular structure (containing both a continuous polymer phase and a continuous pore phase). This structure gives Amberlite XAD-4 polymeric adsorbent excellent physical, chemical and thermal stability. Purchased from Rohm and Haas as a water wet product imbibed with sodium chloride $(\mathrm{NaCl})$ and sodium carbonate $\left(\mathrm{Na}_{2} \mathrm{CO}_{3}\right)$ salts to retard bacterial growth. These salts must be washed from the adsorbent prior to use and it is suggested that this be achieved by washing with water. This resin had a specific surface area of 780 $\mathrm{m}^{2} / \mathrm{g}$, a porosity of $51 \%$ and a pore volume of 0.974 $\mathrm{cm}^{3} / \mathrm{g}$. Prior to impregnation, the resin was washed with deionised water and $\mathrm{NaCl}$ several times to remove inorganic impurities, and then let to dry.

\subsection{Impregnation Procedure}

SIR can be modelled as "a liquid complexing agent dispersed homogenously in a solid polymeric medium". The impregnated agent should behave as in the liquid state but exhibit strong affinity to the matrix. The Amberlite XAD resins are widely-used. As stated above, the attractiveness of SIR lies in the possibility of selecting an existing extractant and adapting it to solve a pressing problem. Naturally, most of the SIR studies so far have been concerned with immediate problems, and the ex- 
tractants chosen have been mostly commercial. They include acidic organo-phosphorous extractant:

a) di(2-ethylhexyl)phosphoric acid (D2EHPA) $[5,25-$ 32].

b) 2-ethylhexylphosphonic acid mono-2-ethylhexyl ester (IONQUEST 801) [13].

c) di(2,4,4-trimethylpentyl)phosphonic acid (CYANEX 272) [13].

The SIR were prepared as dry method most widely used, the extractant, diluted by a solvent, is placed in contact with the polymer, and the solvent is removed by slow evaporation under vacuum. This method is most successful in the impregnation of hydrophilic extractant, such as amines, ethers, esters, etc. An aliquot of extractant (D2EHPA, TOPO and Diphenylthiourea) was diluted in a pre-calculated amount of solvent (n-hexane for D2EHPA and chloroform for the others). The resulting solution was contacted with fresh resin until all organic solution was absorbed by the resins. Finally, these resins were evaporated to remove the solvent in a vacuum.

\subsection{Donnan Dialysis Cell and Procedure}

Dialysis was carried out in a stirred cell represented in Figure 1. The cell consisted of two compartments made of Teflon. The membrane (or membrane and resin) was sandwiched between the two half cells. The effective volume of each cell was $140 \mathrm{ml}$. The feed compartment contains the metal solution at a concentration of $10^{-3} \mathrm{M}$ of metal salt; the other compartment noted strip contains variables concentrations of nitric acid. Each compartment was provided with a vertical mechanical stirrer at stirring speed $600 \mathrm{rpm}$ which was previously determined as high enough to minimise the thickness of the boundary layer. The experiments began when starting the stirring motors in the two compartments of the cell. The exposed membrane area was $7 \mathrm{~cm}^{2}$. All the experiments were performed in a thermostat at $25^{\circ} \mathrm{C}$. The experiment duration has been fixed to six hours and $1 \mathrm{ml}$ of solution has been taken up in the regular time $(1 \mathrm{~h})$ from the feed and strip compartments in the order of the determination of metal ions flux through the membrane.

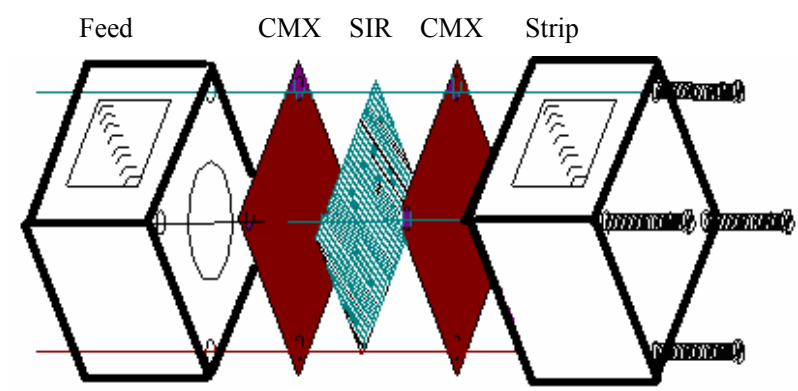

Figure 1. Donnan dialysis cell (hybrid process coupling the SIR to ion-exchange membranes).

\section{Results and Discussion}

\subsection{Effect of the Carrier Nature Impregnated on the Resin}

In the first step, we studied the influence of the nature of the carrier impregnated on the resin XAD-4 using three carriers: Di(2-ethylhexyl)phosphate acid noted (D2EHPA), trioctyl phosphin oxide noted (TOPO) and Diphenylthiourea noted (DPT).

We have fixed the concentration of the carrier to $10^{-2}$ $\mathrm{M}$ and those of nitric acid to $2 \mathrm{M}$, the metals are used as nitrates salt at $10^{-3} \mathrm{M}$. The flux values of the ions were calculated from the slope of the curves given the variation of the amount of the ions transported versus of times.

The obtained results, reported in Table 1, indicate that XAD-4 is characterized by a higher affinity for D2EHPA than TOPO. The use of D2EHPA increases the transport of silver, copper and lead from the feed compartment to the stripping compartment.

These results were confirmed by evaluation of the impregnation process of extractants on resins, as in- dicated in Figure 2. Indeed, the degree of impregnation of the extractant in the resin elution is carried out by a quantity of resin in ethanol which is then titrated with sodium hydroxide $\mathrm{NaOH} 0.1 \mathrm{M}$ in the case of D2EHPA [13, 33-35], or by analysing of samples using UV-Visible

Table 1. Ions fluxes variation using different extractants. $\left[\mathrm{M}^{\mathrm{n}+}\right]=10^{-3} \mathrm{M},\left[\mathrm{H}^{+}\right]=\mathbf{2} \mathrm{M}$ and $[$ extractant $]=10^{-2} \mathrm{M}$.

\begin{tabular}{lccc}
\hline Extractant & $\begin{array}{c}\boldsymbol{J}_{\mathrm{Pb}} \mathbf{1 0} \mathbf{0}^{+10} \\
\left(\mathbf{M o l} / \mathbf{c m}^{\mathbf{2}} \cdot \mathbf{s}^{\mathbf{1}}\right)\end{array}$ & $\begin{array}{c}\boldsymbol{J}_{\mathbf{A g}} \mathbf{1 0}^{+10} \\
\left(\mathbf{M o l} / \mathbf{c m}^{\mathbf{2}} \cdot \mathbf{s}^{\mathbf{1}}\right)\end{array}$ & $\begin{array}{c}\boldsymbol{J}_{\mathrm{Cu}} \mathbf{1 0}^{+10} \\
\left(\mathbf{M o l} / \mathbf{c m}^{\mathbf{2}} \cdot \mathbf{s}^{\mathbf{1}}\right)\end{array}$ \\
\hline TOPO & 15.195 & 1.413 & 4.066 \\
$\begin{array}{l}\text { D2EHPA } \\
\begin{array}{l}\text { Diphenylthio- } \\
\text { urea }\end{array}\end{array}$ & 29.284 & 4.605 & 10.961 \\
\hline
\end{tabular}

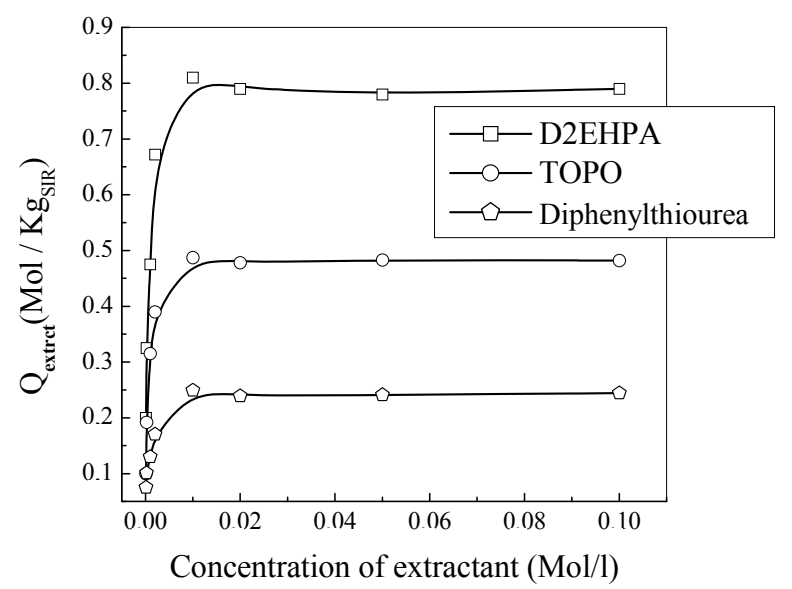

Figure 2. Effect of the concentration of the extractant on the impregnation rate. 
in the case of TOPO and Diphenylthiourea. The three extractants studied, were impregnated into the resin XAD-4 following the dry method. Different concentrations of these extractants were used. Figure 2 shows that the amount of extractant $q_{\text {extr }}\left(\right.$ mole $\left._{\text {extr }} / \mathrm{Kg}_{\mathrm{SIR}}\right)$ adsorbed on the resin increases with its concentration

$C_{\text {extr }}(\mathrm{Mol} / \mathrm{L})$ in the impregnating solution until it reaches saturation. The same result was observed by J. L. Cortina et al. [36] using the XAD-2 as resin, and by M. S. Hosseini et al. [37] who studied the comparison of sorption behaviour of Th(IV) and U(VI) on modified impregnated resin containing quinizarin with that conventional prepared impregnated resin.

The retention of ligands by Amberlite XAD-4 is mainly due to the adsorption phenomenon explained by the interaction of alkyl groups of ligands with vinyl groups and styrene group of the polymer matrix [38].

The maximum adsorption of D2EHPA in the resin is equal to $0.81 \mathrm{~mol} / \mathrm{kg}$ of resin for concentration of D2EHPA equal to $0.01 \mathrm{M}$. This value corresponds to 0.48 $\mathrm{mol} / \mathrm{kg}$ of resin for the TOPO and $0.24 \mathrm{~mol} / \mathrm{kg}$ of resin for diphenylthiourea, this for an extractant concentration equal to $0.01 \mathrm{M}$. The micrography MEB of XAD-4 resin before and after impregnation with different extractant used is given in Figure 3.

The morphologies of different case show that each material present a dense structure where the pores of the resin have been filled by the ligands TOPO, D2EHPA and diphenylthiourea molecules yielding a thick material. It is shown also that D2EHPA is well adsorbed on the resin than TOPO and Diphenylthiourea.
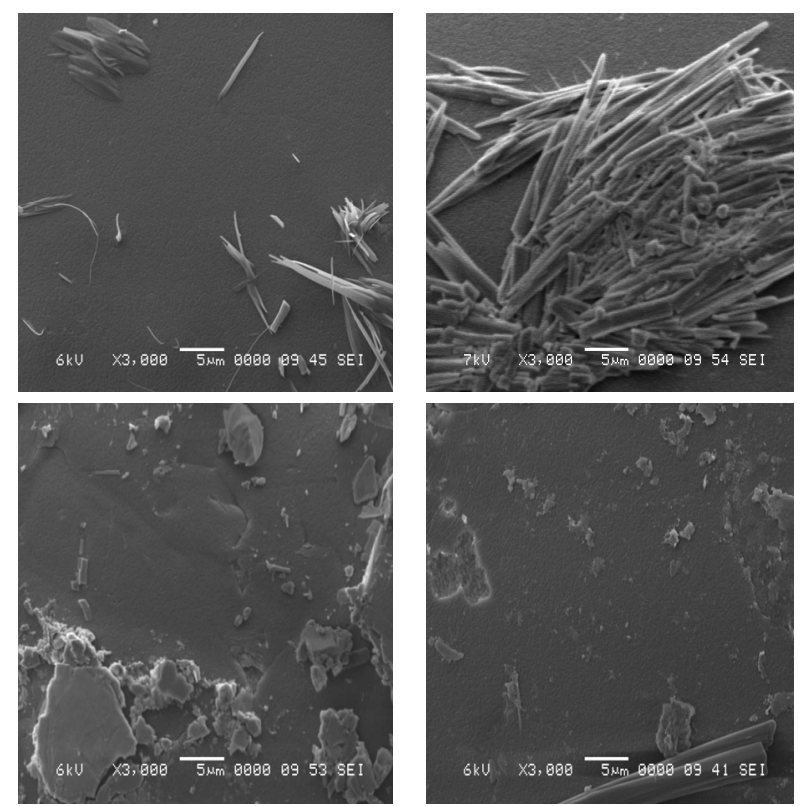

Figure 3. Morphology of XAD-4 resin before impregnation (a) and after impregnation: with D2EHPA (b), with Diphenylthiourea (c) and with TOPO (d).

\subsection{Effect of the Extractant Concentration Impregnated on the Resin}

We have proceeded to study the effect of the concentration of the extractant impregnated on the XAD-4 Amberlite resin to confirm our results in the choice of the D2EHPA as a better extractant especially at $10^{-2} \mathrm{M}$. The concentration of the nitric acid is fixed to $2 \mathrm{M}$ and those of metals are fixed to $10^{-3} \mathrm{M}$. Experiments using a various concentrations of the D2EHPA, TOPO and Diphenylthiourea impregnated on the resin were performed during six hours. Figures 4(a)-(c) represent the ions

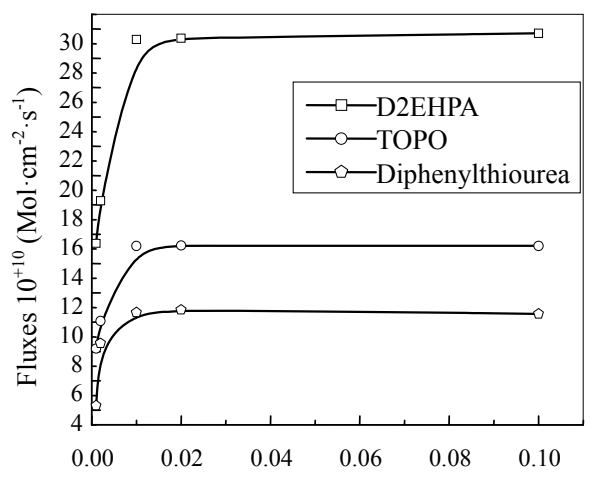

Extractant concentration impregnated on the resin( $\left.\mathrm{Mol}^{-1} \cdot 1\right)$

(a)

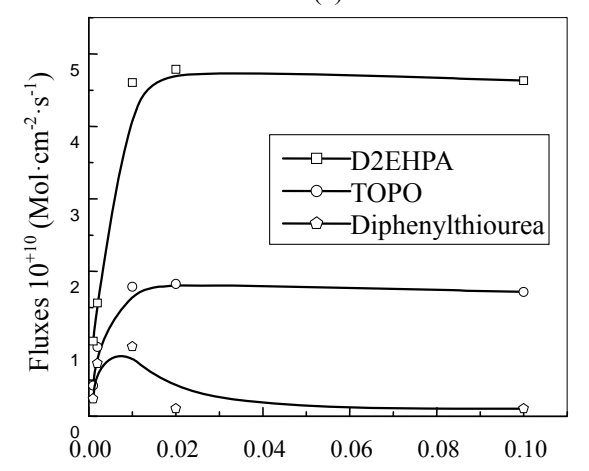

Extractant concentration impregnated on the resin $\left(\mathrm{Mol}^{-1} \cdot 1\right)$ (b)



Extractant concentration impregnated on the resin $\left(\mathrm{Mol}^{-1} \cdot 1\right)$

(c)

Figure 4. Ions fluxes as function of nature of the extractant impregnated on the resin and its concentration: (a) Lead; (b) Silver; (c) Copper. $\left[\mathrm{Cu}^{2+}\right]=\left[\mathrm{Ag}^{+}\right]=\left[\mathrm{Pb}^{2+}\right]=10^{-3} \mathrm{M}$ and $\left[\mathrm{H}^{+}\right]$ $=\mathbf{2}$ M. 
fluxes versus of the extractant concentration impregnated on the resin using three carriers.

It was found that the flux of metallic ions increases with the concentration of three ligands in the resin; however it attains a limit around $10^{-2} \mathrm{M}$ of extractant concentration. This is due to the saturation of the pores of the resin impregnated with the extractant. In order to explain this result, other experiments were conducted in glass columns of $10 \mathrm{~cm}$ long with an inside diameter equal to 4 $\mathrm{mm}$. The experimental procedure has been described in previous studies [1]. Each experiment consists to the introduction of $0.2 \mathrm{~g}$ of impregnated resin in the column, and then it was kept packed with two pieces of glass wool. A volume of $80 \mathrm{ml}$ of solution at various concentrations metal flows along the column at a rate equal to $0.4 \mathrm{ml} / \mathrm{min}$. The outgoing metal solution is recycled to the column, so that the concentration of metal in the tank remains constant. $2 \mathrm{ml}$ samples were taken every five minutes from the tank. The $\mathrm{pH}$ of the aqueous solution recovered is measured using a $\mathrm{pH}$ meter. For each extractant we used three concentrations and we studied the extraction of silver, copper and lead for six hours of time to keep the operating conditions above. Samples are taken at regular time intervals. The obtained results are given in the Figures 5(a)-(c) for lead, silver and copper, respectively.

These figures show that the increasing of the amount of extractant impregnated on the XAD-4 resin, improves the extraction of metals for the three extractants. These results are in perfect agreement with those obtained by Matsunaga et al. [39] which using the PC-88A impregnated on: XAD-4, XAD-2 and XAD-16. On the other hand, when this amount exceeds $0.81 \mathrm{~mol} / \mathrm{kg}$ for D2EHPA SIR, $0.48 \mathrm{~mol} / \mathrm{kg}$ SIR for TOPO and $0.24 \mathrm{~mol} / \mathrm{kg}$ for diphenylthiourea SIR, metal extraction becomes con- stant. This phenomenon has already been obtained by Reyes et al. [40] confirming that the kinetics of extraction is controlled by the saturation of the extractant impregnated in the resin. Other studies $[41,42]$ given on the adsorption kinetics of SIR, showed that the influence of extractant adsorbed on the resin depended of the nature of metals in solution.

\subsection{Effect of the $\mathrm{HNO}_{3}$ Concentration in the Stripping Compartment on the Metal Ions Transport}

The $\mathrm{pH}$ of the receiver solution has a great influence on the transport Flux. In order to investigate this effect on the transport of $\mathrm{Ag}^{+}, \mathrm{Pb}^{2+}$ and $\mathrm{Cu}^{2+}$, different concentrations of nitric acid were used in the stripping compartment with $[$ Extractant $]=10^{-2} \mathrm{M}$ and $\left[\mathrm{M}^{\mathrm{n}+}\right]=10^{-3} \mathrm{M}$.

Figure 6 shows that the quantity of the transported ions increases gradually with the acid concentration inside the stripping compartment; however, it attains a limit after $2.5 \mathrm{M}$ of $\mathrm{HNO}_{3}$. This is due to the osmosis phenomenon which is observed when the difference of the concentration between the two compartments increases, so in order to limit the osmosis phenomenon we work at $2 \mathrm{M}$ concentration of $\mathrm{HNO}_{3}$ in the stripping compartment.

\subsection{Effect of the Metal Ions Concentration in the Feed Compartment}

In order to investigate the effect of initial metal concentration $\left(\mathrm{Ag}^{+}, \mathrm{Pb}^{2+}\right.$ and $\left.\mathrm{Cu}^{2+}\right)$ in the feed compartment on the metal ions transport, the concentration of this latter was varied from $10^{-4} \mathrm{M}$ to $10^{-2} \mathrm{M}$ with just distilled water in the receiver compartment (Figure 7). The concentration of D2EHPA was fixed to $10^{-2} \mathrm{M}$. The results show
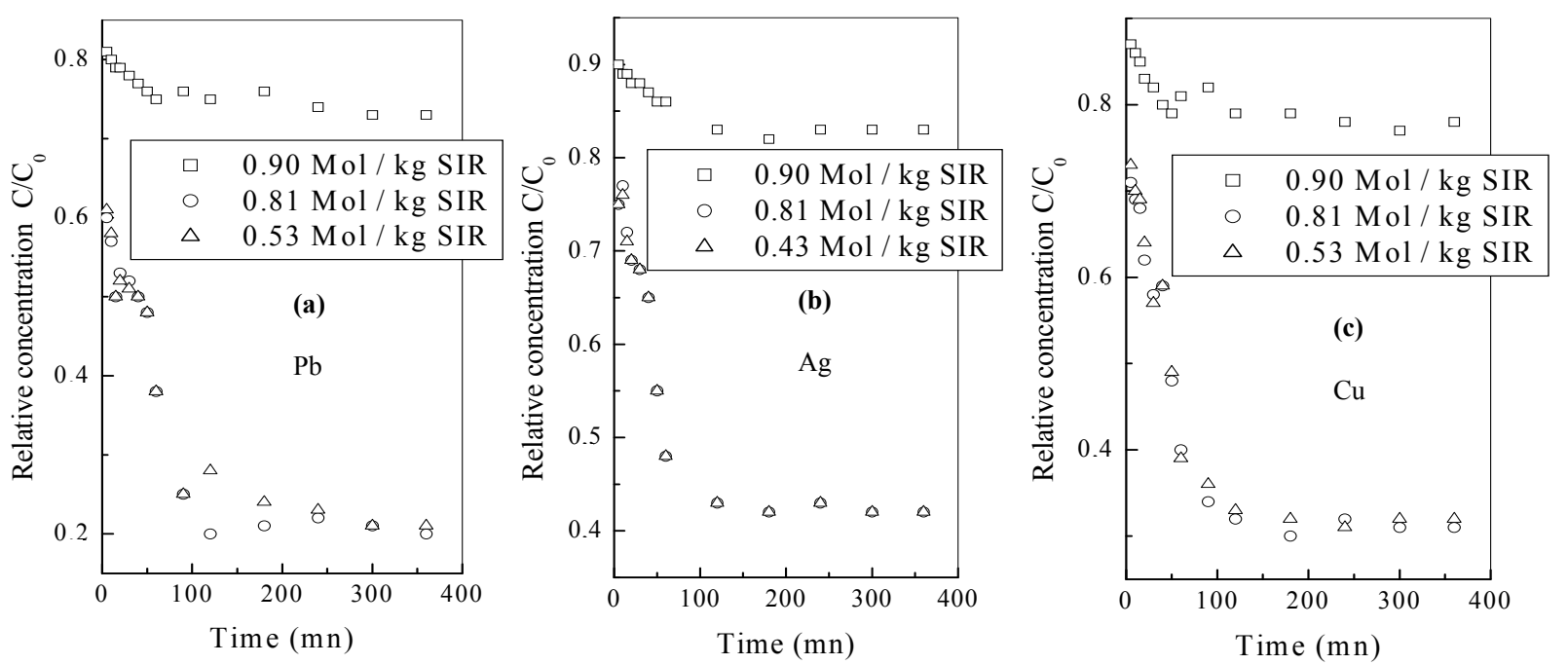

Figure 5. The variation of the relative concentration of metallic ions at different concentrations of D2EHPA, $\left[\mathrm{M}^{\mathrm{n}+}\right]=10^{-3} \mathrm{M}$, $\mathrm{pH}_{\text {initial }}=\mathbf{5 . 5}$. 


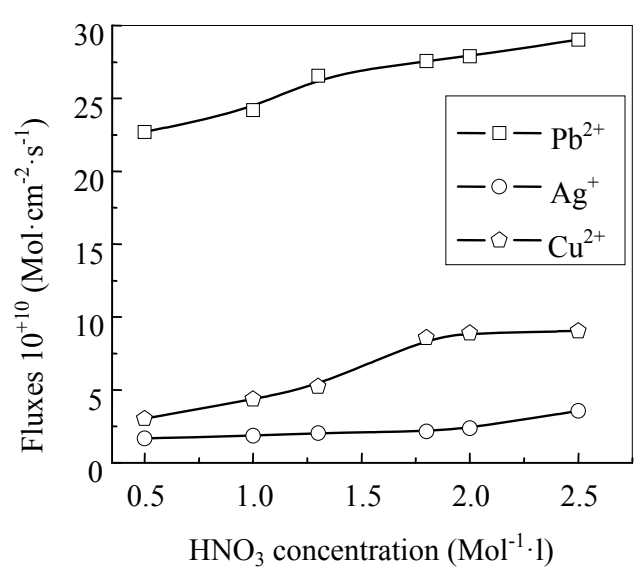

Figure 6. Ions fluxes as a function of concentration of nitric acid in the stripping compartment: $[$ D2EHPA $]=10^{-2} \mathrm{M}$ and $\left[\mathbf{M}^{\mathrm{n}+}\right]=\mathbf{1 0}^{-3} \mathbf{M}$.

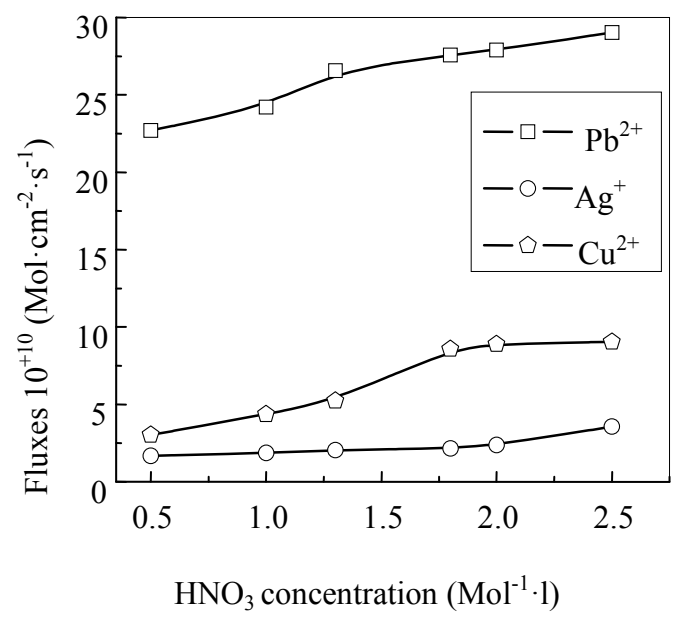

Figure 7. Ions fluxes as a function of concentration of metal ions in the feed compartment. [D2EHPA $]=10^{-2} \mathrm{M}$.


Figure 8. The time variation of the relative concentration of $M^{\mathbf{n}+}$ at different pH: Extractant: D2EHPA, (a) Lead; (b) Silver; (c) Copper.

that the increasing of the amount of metals improves the transport of these ions from the feed compartment to the stripping compartment.

\subsection{Influence of pH Solution on the Phenomenon of Extraction}

The initial values of $\mathrm{pH}$ were fixed as 2.6, 3.6 and 6.6. The concentrations of the metal ions and the extractant are equals to $10^{-3} \mathrm{M}$ and to $10^{-2} \mathrm{M}$, respectively. The samples were taken at regular time. $\mathrm{pH}$ value and concentration are given for each solution.

The $\mathrm{pH}$ of the solution have a great influence on the adsorption kinetics at the equilibrium, it was recognized that this importance is related to the shape of the metal in solution but also to the functional groups of the extractant adsorbed on the resin.

The Figures 8(a)-(c), show the variation of the amount of metal adsorbed on the resin XAD-4 as a function of time for different extractants and at different initial $\mathrm{pH}$ values of the metal solution.

These figures show that when the $\mathrm{pH}$ varies from 2.6 to 6.6 , the kinetics of extraction becomes faster. This indicates that the $\mathrm{pH}$ improves the extraction of metals. These results agree with those obtained in other works $[42,43]$. J. L. Cortina et al. [44] showed that metal extraction is $\mathrm{pH}$ dependent with the general low: the important extraction of metals is induced by an increase in $\mathrm{pH}$.

\section{Conclusions}

This work has helped to highlight a new hybrid process coupling the SIR to ion-exchange membranes for the separation and recovery of heavy metals.

The first part of this work, is reported to the study of 
the influence of coupling SIR and ion-exchange membranes by means of Donnan dialysis on the elimination of copper(II), lead(II) and silver(I).

The results show that the use of D2EHPA is the best choice for best yields of concentration and separation of the three metal ions used. The study realized in a second part of this work was to see the influencing of some parameters on the adsorption of different metal used on the XAD-4 resin, previously impregnated by three extractants. Indeed, the extraction of copper(II), lead(II) and silver(I) was carried out by using D2EHPA, TOPO and diphenylthiourea impregnated on the resin. The different parameters such as: the influence of carrier concentration on the degree of impregnation, and the results obtained confirm that the D2EHPA adsorbs better to the surface of XAD-4 compared to the other two extractants. The application of SIR to the extraction of silver, copper and lead showed high selectivity of the three metals towards D2EHPA, with a greater yield for copper and lead than silver. The results of the study of the influence of $\mathrm{pH}$ of the aqueous solution on the extraction of metal cations, showed that the $\mathrm{pH}$ improves the adsorption of metals on the XAD-4/Ligand resin.

\section{Acknowledgements}

Authors thank again Doctor AROUS Omar for Scientific and Technical assistance.

\section{REFERENCES}

[1] J. Serarols, J. Poch, M. F. Llop and I. Villaescusa, "Determination of the Effective Diffusion Coefficient for Gold(III) on Macroporous Resin XAD2 Impregnated with Triisobutyl Phosphine Sulfide," Reactive and Functional Polymers, Vol. 41, No. 1-2, 1999, pp. 27-35. doi:10.1016/S1381-5148(99)00020-6

[2] N. Swami and D. B. Dreisinger, "Kinetics of Zinc Removal from Cobalt Electrolytes by Ion Exchange," Solvent Extraction and Ion Exchange, Vol. 13, No. 6, 1995, pp. 1037-1062. doi:10.1080/07366299508918317

[3] A. Warshawsky, "Extraction with Solvent-Impregnated Resins," In: J. A. Marinsky and Y. Marcus, Eds., Ion Exchange and Solvent Extraction, Vol. 8, Marcel Dekker, New York, 1981, pp. 229-310.

[4] J. L. Cortina, N. Miralles, M. Aguilar, A. M. Sastre, A. Profumo and M. Pesavento, "Solvent-Impregnated Resins Containing Di-(2,4,4-trimethylpentyl) Phosphonic Acid I. Comparative Study of Di-(2,4,4-trimethylpentyl) Phosphinic Acid Adsorbed into Amberlite XAD-2 and Dissolved in Toluene," Reactive Polymers, Vol. 21, No. 1-2, 1993, pp. 89-101. doi:10.1016/0923-1137(93)90057-M

[5] J. L. Cortina, N. Miralles, M. Aguilar and A. M. Sastre, "Solvent Impregnated Resins Containing Di-(2-ethylhexyl) Phosphoric Acid. I. Preparation and Study of the Retention and Distribution of the Extractant on the Resin," Solvent Extraction and Ion Exchange, Vol. 12, No. 2,
1994, pp. 349-369. doi:10.1080/07366299408918214

[6] A. Warshawsky and A. Patchrnik, "Recent Developments in Metal Extraction by Solvent Impregnated Resin," In: M. Streat (Ed.), The Theory and Practice of Ion Exchange, SCI, London, 1976, pp. 381-384.

[7] V. A. Lemos and P. X. Balia, "Amberlite XAD-2 Functionnalzed with 2-Amin Othiophenol as a New Sorbent for On-Line Preconcentration of Cadmium and Copper," Talanta, Vol. 67, No. 3, 2005, pp. 564-570. doi:10.1016/j.talanta.2005.03.012

[8] E. J. dos Santos, A. B. Herrmann, A. S. Ribeiro and A. J. Curtius, "Determination of $\mathrm{Cd}$ in Biological Samples by Flame AAS Following On-Line Preconcentration by Complexation with $O, O$-diethyldithiophosphate and Solid Phase Extraction with Amberlite XAD-4," Talanta, Vol. 65, No. 2, 2005, pp. 593-597. doi:10.1016/j.talanta.2004.07.025

[9] S. Baytak and A. R. Turker, "The Use of Agrobacterium Tumefacients Immobilized on Amberlite XAD-4 as a New Biosorbent for the Column Preconcentration of Iron(II), Cobalt(II), Manganese(II), and Chromium(III)," Talanta, Vol. 65, No. 4, 2005, pp. 938-945. doi:10.1016/j.talanta.2004.08.021

[10] A. Uzun, M. Soylak and L. Elçi, "Preconcentration and Separation with Amberlite XAD-4 Resin; Determination of $\mathrm{Cu}, \mathrm{Fe}, \mathrm{Pb}, \mathrm{Ni}, \mathrm{Cd}$, and $\mathrm{Bi}$ at Trace Levels in Waste Water Samples by Flame Atomic Absorption Spectrometry," Talanta, Vol. 54, No. 1, 2001, pp. 197-202. doi:10.1016/S0039-9140(00)00669-X

[11] Y. Liu, X. Chang, S. Wang, Y. Guo, B. Din and S. Meng, "Solid-Phase Spectrophotometric Determination of Nickel in Water and Vegetable Samples at Sub- $\mu \mathrm{g} 1^{-1}$ Level with $o$-Carboxylphenyl Diazoaminoazobenzene Loated XAD-4," Talanta, Vol. 64, No. 1, 2004, pp. 160-166. doi:10.1016/i.talanta.2004.02.002

[12] B. N. Singh and B. Maiti, "Separation and Preconcentration of U(VI) on XAD-4 Modified with 8-Hydroxy Quinoline," Talanta, Vol. 69, No. 2, 2006, pp. 393-396. doi:10.1016/j.talanta.2005.06.072

[13] A. G. Strikovsky, K. Jerabek, J. L. Cortina, A. M. Sastre and A. Warshawsky, "Solvent Impregnated Resin (SIR) Containing Dialkyl Dithiophosphoric Acid on Amberlite XAD-2: Extraction of Copper and Comparison to the Liquid-Liquid Extraction," Reactive and Functional Polymers, Vol. 28, No. 2, 1996, pp. 149-158. doi:10.1016/1381-5148(95)00060-7

[14] J. L. Cortina and N. Miralles, "Kinetic Studies on Heavy Metal Ions Removal by Impregnated Resins Containing Di-(2,4,4-trimethylprntyl) Phosphine Acid," Solvent Extraction and Ion Exchange, Vol. 15, No. 6, 1997, pp. 1064-1068. doi:10.1080/07366299708934522

[15] I. Villaescusa, V. Salvado and J. De. Pablo, "Liquid-Liquid and Solid-Liquid Extraction of Gold by Trioctylmethylammoniumchloride (TOMACI) Dissolved in Toluene and Impregnated on Amberlite XAD-2 Resin," Hydrometallurgy, Vol. 41, No. 2-3, 1996, pp. 303-311. doi:10.1016/0304-386X(95)00064-N

[16] J. L. Cortina, N. Miralles, M. Aguilar and A. M. Sastre, "Solvent Impregnated Resins Containing 
Di-(2-ethylhexyl)Phosphoric Acid. II. Study of the Distribution Equilibria of $\mathrm{Zn}, \mathrm{Cu}$ and Cd," Solvent Extraction and Ion Exchange, Vol. 12, No. 2, 1994, pp. 371-391. doi:10.1080/07366299408918215

[17] J. L. Cortina, N. Miralles, A. M.Sastre and M. Aguilar, "Solid-Liquid Extraction Studies of Divalent Metals with Impregnated Resins Containing Mixtures of Organophosphorus Extractants," Reactive and Functional Polymers, Vol. 32, No. 3, 1997, pp. 221-229.

doi:10.1016/S1381-5148(96)00083-1

[18] K. Ohto, Y. Tanaka, M. Yano, T. Shinohara, E. Murakami and K. Inoue, "Selective Adsorption of Lead Ion on Calix[4]Arene Carboxylate Resin Supported by Polyallylamine," Solvent Extraction and Ion Exchange, Vol. 19, No. 4, 2001, pp. 725-741. doi:10.1081/SEI-100103817

[19] Q. Jia, Z. H. Wang, D. Q. Li and C. J. Niu, “Adsorption of Heavy Rare Earth(III) with Extraction Resin Containing Bis(2,4,4-trimethylpentyl) Monothiophosphinic Acid," Journal of Alloys and Compounds, Vol. 374, No. 1-2, 2004, pp. 434-437. doi:10.1016/j.jallcom.2003.11.056

[20] P. Miranda, M. F. Maduar, G. Vicentini, L. B. Zinner, N. M. P. de Moraes and H. M. Shihomatsu, "Study of the Rare Earth Elements Fractionation by Solvent Extraction: Use of HPLC as an Analytical Control Technique," Journal of Alloys and Compounds, Vol. 344, No. 1-2, 2002, pp. 46-50. doi:10.1016/S0925-8388(02)00303-1

[21] Q. Jia, C.H. Zhan, D. Q. Li and C. J. Niu, "Extraction of Zinc(II) and Cadmium(II) by Using Mixtures of Primary Amine N1293 and Organophosphorus Acids," Separation Science and Technology, Vol. 39, No. 5, 2004, pp. 11111123. doi:10.1081/SS-120028574

[22] Y. Guo, B. Din, Yi Liu, X. Chang, S. Meng and J. Liu, "Preconcentration and Determination of Trace Elements with 2-Aminoacetylthiophenol Functionalized Amberlite XAD-2 by Inductively Coupled Plasma-Atomic Emission Spectrometry," Talanta, Vol. 62, No. 1, 2004, pp. 207213. doi:10.1016/S0039-9140(03)00423-5

[23] B. Godlewska-Zylkiewicz, "Microorganism in Inorganic Chemical Analysis," Analytical and Bioanalytical Chemistry, Vol. 384, No. 1, 2006, pp. 114-123. doi:10.1007/s00216-005-0142-2

[24] M. Dogru, R. Gul-Guven and Sait Erdogan, "The Use of Bacillus Subtilis Immobilized on Amberlite XAD-4 as a New Biosorbent in Trace Metal Determination," Journal of Hazardous Materials, Vol. 149, No. 1, 2007, pp. 166173. doi:10.1016/j.jhazmat.2007.03.066

[25] T. Saitoh, F. Nakane and M. Hiraide, "Preparation of Trioctylamine-Impregnated Polystyrene-Divinylbenzene Porous Resins for the Collection of Precious Metals from water," Reactive and Functional Polymers, Vol. 67, No. 3, 2007, pp. 247-252. doi:10.1016/j.reactfunctpolym.2006.12.001

[26] E. Metwally, "Kinetic Studies for Sorption of Some Metal Ions from Aqueous Acid Solutions onto TDA Impregnated Resin," Journal of Radioanalytical and $\mathrm{Nu}$ clear Chemistry, Vol. 270, No. 3, 2006, pp. 559-566. doi:10.1007/s10967-006-0462-5

[27] J. K. Moon, Y. Han, C. Jung, E. Lee and B. Lee, “Adsorption of Rhenium and Rhodium in Nitric Acid Solu- tion by Amberlite XAD4 Impregnated with Aliquat 336," Korean Journal of Chemical Engineering, Vol. 23, No. 2, 2006, pp. 303-308. doi:10.1007/BF02705732

[28] S. Befler, E. Komgold and Y. Egozy, Ion-Exchange Technology, In: D. Naden and M. Streat, Eds., London, Vol. 736, 1984.

[29] S. Rengaraj, Y. Kim, C. K. Joo, K. Choi and J. Yi, "Batch Adsorptive Removal of Copper Ions in Aqueous Solutions by Ion Exchange Resins: $1200 \mathrm{H}$ and IRN97H," Korean Journal of Chemical Engineering, Vol. 21, No. 1, 2004, pp. 187-194. doi:10.1007/BF02705397

[30] S. Marinez, A. M. Sastre, N. Miralles and F. J. Alguacil, "Gold(III) Extraction Equilibrium in the System Cyanex 923-HCl Au(III)," Hydromettalurgy, Vol. 40, No. 1-2, 1996, pp. 77-88. doi:10.1016/0304-386X(94)00084-G

[31] N. Kabay, M. Demircioglu, H. Ekinci, M. Saglam and M. Streat, "Extraction of Cd(II) and $\mathrm{Cu}(\mathrm{II})$ from Phosphoric Acid Solutions by Solvent-Impregnated Resins (SIR) Containing Cyanex 302," Reactive and Functional Polymers, Vol. 38, No. 2-3, 1998, pp. 219-226. doi:10.1016/S1381-5148(98)00034-0

[32] X. Zhao, Q. Jia and X. Zhou, "Adsorption of Zinc(II), Cadmium(II) and Copper(II) with PTFE Selective Resin Containing Primary Amine N1923 and Cyanex925," Korean Journal of Chemical Engineering, Vol. 26, No. 6, 2009, pp. 1729-1732. doi:10.1007/s11814-009-0241-4

[33] O. Arous, F. Saad Saoud, M. Amara and H. Kerdjoudj, "Efficient Facilitated Transport of Lead and Cadmium across a Plasticized Triacetate Membrane Mediated by D2EHPA and TOPO," Materials Sciences and Applications, Vol. 2, No. 6, 2011, pp. 615-623. doi: $10.4236 / \mathrm{msa} .2011 .26083$

[34] M. P. Gonzales, I. Saucedo, R. Navarro, M. Avila and E. Guibal, "Selective Separation of Fe(III), Cd(II) and Ni(II) from Dilute Solutions Using Solvent Impregnated Resins," Industrial \& Engineering Chemistry Research, Vol. 40, No. 25, 2001, pp. 6004-6013. doi:10.1021/ie010071m

[35] J. L. Cortina, N. Miralles, A. M. Sastre and M. Aguiar, "Solid-Liquid Extraction Studies of $\mathrm{Zn}(\mathrm{II}), \mathrm{Cu}(\mathrm{II})$ and Cd(II) from Chloride Media with Impregnated Resins Containing Mixtures of Organophosphorus Compounds Immobilized on to Amberlite XAD2," Hydromettalurgy, Vol. 37, No. 3, 1995, pp. 301-322. doi:10.1016/0304-386X(94)00029-3

[36] J. L. Cortina, R. Arad-Yellin, N. Miralles, A. M. Sastre and A. Warshawsky, "Kinetics Studies on Heavy Metal Ions Extraction by Amberlite XAD2 Impregnated Resins Containing a Bifunctional Organophosphorous Extractant," Reactive and Functional Polymers, Vol. 38, No. 2-3, 1998, pp. 269-278. doi:10.1016/S1381-5148(98)00053-4

[37] M. S. Hosseini and A. H. Bandegharaei, "Comparison of Sorption Behaviour of Th(IV) and U(VI) on Modified Impregnated Resin Containing Quinizarin with that Conventional Prepared Impregnated Resin," Journal of Hazardous Materials, Vol. 190, No. 1-3, 2011, pp. 755-765. doi:10.1016/j.jhazmat.2011.03.111

[38] K. Yoshizuka, Y. Sakomoto, Y. Baba and K. Inoue, "Distribution Equilibria in the Adsorption of Cobalt(II) and 
Nickel(II) on Levextrel Resin Containinig Cyanex 272," Hydromettalurgy, Vol. 23, No. 2-3, 1990, pp. 309-318. doi:10.1016/0304-386X(90)90012-Q

[39] H. Matsunaga, A. Ismail, Y. Wakui and T. Yokoyama, "Extraction of Rare Earth Elements with 2-Ethylhexyl Hydrogen 2-Ethylhexyl Phosphonate Impregnated Resins Having Different Morphology and Reagent Content," Reactive and Functional Polymers, Vol. 49, No. 3, 2001, pp. 189-195. doi:10.1016/S1381-5148(01)00077-3

[40] L. H. Reyes, I. S. Medina, R. N. Mendoza, J. R. Vazquez, M. A. Rodriguez and E. Guibal, "Extraction of Cadmium from Phosphoric Acid Using Resins Impregnated with Organo Phosporus Extractants," Industrial \& Engineering Chemistry Research, Vol. 40, No. 5, 2001, pp. 14221433.

[41] R. S. Juang and H. C. Lin, "Metal Sorption with Extractant-Impregnated Macroporous Resins. 1. Particle Diffusion Kinetics," Journal of Chemistry Technology and
Biotechnology, Vol. 62, No. 2, 1995, pp. 132-140. doi: $10.1002 /$ jetb. 280620204

[42] R. S. Juang and S. H. Lee, "Metal Sorption with Extractant-Impregnated Macroporous Resins. 2. Chemical Reaction and Particle Diffusion Kinetics," Journal of Chemistry Technology and Biotechnology, Vol. 62, No. 2, 1995, pp. 141-147. doi:10.1002/jctb.280620205

[43] M. Blahusiak, S. Schlosser and J. Martak, "Extraction of Butyric Acid by a Solvent Impregnated Resin Containing Ionic Liquid," Reactive and Functional Polymers, Vol. 71, No. 7, 2011, pp. 736-744. doi:10.1016/j.reactfunctpolym.2011.04.002

[44] J. L. Cortina, N. Miralles, M. Aguilar and A. M. Sastre, "Extraction Studies of $\mathrm{Zn}(\mathrm{II}), \mathrm{Cu}(\mathrm{II})$ and $\mathrm{Cd}(\mathrm{II})$ with Impregnated and Levextrel Resins Containing Di(2-ethylhexyl)Phosphoric Acid," Hydrometallurgy, Vol. 36, No. 2, 1994, pp. 131-142. doi:10.1016/0304-386X(94)90001-9 